\title{
Colour differentiation in a coral reef fish throughout ontogeny: habitat background and flexibility
}

\author{
Bruno Frédérich ${ }^{1}$, Suzanne C. Mills ${ }^{2}$, Mathieu Denoël ${ }^{3}$, Eric Parmentier ${ }^{1}$, \\ Christophe Brié ${ }^{4}$, Raphael Santos ${ }^{5}$, Viliame Pita Waqalevu ${ }^{6}$, David Lecchini ${ }^{7, *}$ \\ ${ }^{1}$ Laboratoire de Morphologie fonctionnelle et évolutive, Institut de Chimie (B6c), Université de Liège, 4000 Liège, Belgium \\ ${ }^{2}$ Unité mixte de recherche (UMR) 5244 CNRS-EPHE-UPVD, Université de Perpignan, 66860 Perpignan, France \\ ${ }^{3}$ Laboratory of Fish and Amphibian Ethology, Behavioural Biology Unit, Université de Liège, 4000 Liège, Belgium \\ ${ }^{4}$ Tropical Fish Tahiti, 98745 Rangiroa, French Polynesia \\ ${ }^{5}$ Unité de service et de recherche (USR) 3278 CNRS-EPHE, CRIOBE, 98729 Moorea, French Polynesia \\ ${ }^{6}$ Institute of Marine Resources, Aquaculture Laboratory, University of the South Pacific, Suva, Fiji \\ ${ }^{7}$ Institut de Recherche pour le Développement, Centre IRD Noumea, UR 227 CoReUs, 98848 Noumea, New Caledonia
}

\begin{abstract}
Colour polymorphism is widespread in animals but, in contrast to other types of polymorphism, has been little explored during ontogeny. Among coral reef fish, the surge damselfish Chrysiptera leucopoma settles in the larval stage as a yellow morph, whereas 2 colour morphs (yellow and brown) are apparent in adults at Rangiroa Atoll, French Polynesia. To understand this dimorphism, we tested, under controlled conditions, the hypotheses that: (1) environmental cues (habitat background and conspecific density) play important roles in morph differentiation during ontogeny and (2) morph colouration is reversible. Our first experiment showed that a dark habitat background induced the formation of the brown morph, while C. leucopoma larvae kept their yellow morph when placed in aquaria with a bright habitat background. Colour change from yellow to brown also occurred within the bright habitat, but only at high conspecific densities. Our second experiment showed that colour change was reversible within $15 \mathrm{~d}$ post-settlement, but not at the adult stage. Overall, our results highlighted that the studied polymorphism may be environmentally induced and reversible during the first post-settlement days of this coral reef fish.
\end{abstract}

KEY WORDS: Colour morph · Chrysiptera leucopoma $\cdot$ Environmental factors

\section{INTRODUCTION}

Colour polymorphism, defined as the presence of 2 or more distinct colour morphs within a single interbreeding population, is a widespread phenomenon across the animal kingdom (e.g. gastropods, insects, crustaceans, fishes, mammals; Gray \& McKinnon 2007). For example, a number of coral reef fishes are characterized by dimorphism involving yellow and dark variants, including the butterflyfish Forcipiger longirostris, the goatfish Parupeneus cyclostomus and the dottyback Pseudochromis fuscus (see Messmer et al. 2005). For P. fuscus, Munday et al. (2003) have postulated that the colour dimorphism repre- sents aggressive mimicry. Environmental factors determining the colour of polymorphic species (i.e. colour polyphenism) include habitat background, food composition, food availability, temperature, water depth and population density or level of predation risk (for review, see Leimar 2007). Through phenotypic plasticity, an organism can adapt to a particular environment, but the inducer (i.e. environmental factor) is not necessarily the same as the selective environment (Noor et al. 2008). As exemplified in insects by Nijhout (2003), factors such as temperature, rearing density and food compounds are distinct from the presumed adaptive-induced phenotypes (e.g. aposematism, crypsis). Other inducers, such 
as habitat background, light intensity or reflectance may directly act by inducing a resemblance-tosurroundings phenotype. This last type of polyphenism is advantageous because flexibility to changing environments may be retained (Noor et al. 2008). Moreover, colour polyphenism can be highly adaptive for animals that experience habitat shifts during ontogeny. For example, neonates of the tropical python Morelia viridis hatch either yellow or red, and both morphs change to green with age (Wilson et al. 2006). Colour change from red or yellow to green provides camouflage from visually oriented avian predators in the different habitats used by juveniles (i.e. on the ground at the rainforest edge) and adults (i.e. in the canopy of rainforest) (Wilson et al. 2007). Thus colour polymorphism is widespread in animals but, in contrast to other types of polymorphism, has been little explored during ontogeny (for review, see Leimar 2007).

The surge damselfish Chrysiptera leucopoma is a herbivorous damselfish commonly found on IndoPacific coral reefs (Allen 1991). After oceanic dispersal, bright yellow C. leucopoma larvae with a dorsal blue line colonize lagoons (Lo-Yat 2002). In contrast to the single colour morph during the larval phase, C. leucopoma adults have 2 distinct colour morphs: (1) the larval colour, a bright yellow body with a dorsal blue line, and (2) a dark brown body with or without a vertical white bar down the middle of its body (Allen 1991). In French Polynesian lagoons, C. leucopoma defend individual territories, graze algae from the substrate and use small holes as refuges (Lecchini \& Galzin 2005). Yellow morph adults are usually found on live coral colonies or coral rubble (i.e. bright habitat background), while brown morph adults are always found hiding cryptically in coral slab or beach-rock (i.e. dark habitat background; Lecchini 2003). At settlement, newly settled individuals use the same habitat as adults, and the adults are aggressive toward similarly sized conspecifics (Lecchini 2003, Lecchini \& Galzin 2005). Overall, the present study aimed to investigate the environmental factors inducing colour change in C. leucopoma and the potential flexibility (i.e. reversibility of colour imprinting) in these mechanisms across different ontogenetic stages (larval, juvenile and adult).

First, we experimentally tested 2 environmental factors that might influence the determinism of Chrysiptera leucopoma coloration during post-settlement ontogeny: (1) colour of the habitat background and (2) conspecific density. Second, we determined the reversibility of colour morph change with respect to habitat background and conspecific density. Last, we compared the flexibility of colour morph change at 2 different life stages, settlement and adulthood.

\section{MATERIALS AND METHODS}

Sampling site. This study was conducted at Rangiroa Atoll $\left(15^{\circ} 07^{\prime} \mathrm{S}, 147^{\circ} 38^{\prime} \mathrm{W}\right)$, French Polynesia, during August and October 2007 and May 2008.

Sampling protocol. Nets were fixed to the reef crest at dusk and Chrysiptera leucopoma larvae reaching the reef during the night were collected at dawn using crest nets (Lecchini et al. 2004). A total of 206 C. leucopoma larvae (mean \pm SD standard length $=14.2 \pm$ $0.4 \mathrm{~mm}$ ) were captured and randomly assigned to an environmental treatment. During the experiment, fish were fed Artemia sp. nauplii 5 times a day.

The experiment consisted of a factorial design with 2 environmental treatments: habitat (bright and dark) and conspecific density (number of fish per aquaria). For the habitat treatment, each aquarium (with continuous water input) was divided into 2 compartments $(20 \times 15 \times 30 \mathrm{~cm})$ and manipulated in order to represent bright and dark habitats from the field. The bright habitat compartments were left with original translucent glass panes, whereas the dark habitat consisted of a large dark grey plastic cylinder suspended in the aquaria, in which Chrysiptera leucopoma were placed, with the upper opening above water level and the lower opening closed by a net. Both compartments had a similar volume of seawater (8.1 and 7.8 , respectively) and were exposed to natural sunlight. Density treatments were carried out simultaneously in the bright and dark habitat compartments of the same aquarium where the same number of $C$. leucopoma $(1,5,10$ or 20$)$ were present in each compartment.

Preliminary experiments (based on 30 Chrysiptera leucopoma) revealed that colour morphs (yellow: bright yellow body with a dorsal blue line; brown: dark brown body with or without a vertical white bar) became apparent in larvae after $5 \mathrm{~d}$ in experimental aquaria. Therefore, the experimental duration was set to $5 \mathrm{~d}$, after which the larvae were removed and their colour noted. Moreover, some C. leucopoma were kept in the same habitat for $15 \mathrm{~d}$ and the fish were manipulated every $5 \mathrm{~d}$ (dark to dark habitats or bright to bright habitats) to be sure that the fish manipulation did not induce the colour change. Lastly, we observed that some fish had an intermediate morph (yellow body with a dorsal blue line plus a vertical white bar present down the middle of the body). We could assume that the intermediate morph was in the process of changing into either a brown or a yellow morph. However, some coral reef fishes can display a vertical white bar either temporarily or permanently while kept in aquaria. This colouring is also often seen in behavioural reproductive interactions or aggressive interactions in the field.

Environmental cues for colour morphs: habitat and density. We tested the effect of habitat (bright and 
dark) and conspecific density $(1,5,10$ and 20 conspecifics) on the colour morphs of Chrysiptera leucopoma larvae. Larvae were put in the bright and dark habitat compartments and, after $5 \mathrm{~d}$, colour morph was recorded for each individual.

Larvae were randomly assigned to a habitat and density treatment. However, due to the number of larvae available (i.e. variability of larval flux during reef settlement events), we were unable to carry out the same number of replicates for each density. The number of replicates carried out per density $(1,5,10$ and 20) was $3,4,4$ and 2 , respectively; therefore, a total of 26 experimental trials were carried out, 13 in each habitat.

The percentage of brown morphs was obtained from the sum of all fishes per trial where a yellow morph was scored as 0, a brown morph as 1 and an intermediate morph as 0.5 . These sums were then divided by the total density per trial, i.e. $1,5,10$ or 20 . The use of percentages takes into account the low level of mortality observed during the experiment $(<3 \%)$. Percentages were arcsine-square root transformed to meet the assumptions of normality and homogeneity of variance. Statistical tests may suffer from the low number of replicates for each density treatment, but the replicates depended on the number of larvae collected in crest nets. Consequently, to improve the statistical power, density was categorized into 2 groups: low density (results of density treatments 1 and 5) and high density (results of density treatments 10 and 20) treatments. We used a 2-way ANOVA to examine the effects of 2 fixed factors: habitat (dark and bright) and density (low and high) on percentage of brown morphs. Multivariate analysis of variance (MANOVA) was used to break down the interaction term, by analyzing the effect of one independent variable (e.g. habitat) at individual levels of the other independent variable (e.g. density). Syntax in SPSS (version 17, 2008) was used to perform these analyses (Field 2005).

Colour morph flexibility and environmental cues. Juveniles: Individuals (i.e. 1, 5, 10 or 20 fish) initially placed in a bright habitat were transferred to a dark habitat and subsequently transferred back to a bright habitat, each for a duration of $5 \mathrm{~d}$, and vice versa for those individuals initially placed in a dark habitat.

Density and habitat effects inducing the brown colour morph were tested using a 2-way ANOVA. In this test, the percentage of brown morphs (arcsinesquare root transformed) was considered as an independent variable, with density and habitat as fixed factors. The null hypothesis that environmental change did not induce a reversal of colour was tested using 2-way analyses of covariance (ANCOVA) to examine the effects of habitat (fixed factor, 2 levels: bright and dark) and density (fixed factor, 2 levels: low and high) on the difference in the percentage of brown morphs. The difference in the percentage of brown morphs was arcsine-square root transformed to meet the assumptions of normality and homogeneity of variance. We included (arcsine-square root transformed) the percentage of brown morphs from the previous trial as a covariate. As described above, MANOVA was used to examine the interaction terms.

Adults: To test if colour flexibility can occur during the adult stage and in response to environmental cues, Chrysiptera leucopoma adults were collected in Rangiroa Lagoon at their respective natural habitat (i.e. live corals for yellow morphs and coral slab/ beach-rock for brown morphs) with small nets. The fish were kept for $24 \mathrm{~h}$ in aquaria before being tested (fish were maintained individually in aquaria, $20 \times$ $20 \times 20 \mathrm{~cm}$, supplied with flow-through seawater from the adjacent lagoon, and without any added artificial or natural habitats). The experimental design consisted of 2 treatments: habitat (bright and dark) and density (1, 5, and 10 adult conspecifics). Eight, 4 and 4 replicates were carried out for the densities of 1, 5 and 10, respectively, with adult yellow morphs captured. Due to logistical problems, only 3 replicates were carried out for a density of 5 fish with adult brown morphs. Colour morph was noted after $5 \mathrm{~d}$ of treatment.

\section{RESULTS}

\section{Environmental cues for colour morphs (habitat and density)}

A significantly higher proportion of brown colour morphs was observed after a 5 d period postsettlement in the dark habitat compared to bright habitat (Table 1, Fig. 1) at all conspecific densities (MANOVA, low density: $F_{1,23}=188.29, \mathrm{p}<0.001$; high density: $\left.F_{1,23}=57.56, \mathrm{p}<0.001\right)$. In contrast, a significantly higher proportion of yellow colour morphs was observed in the bright habitat (Fig. 1), even if some brown colour morphs appeared at high density (MANOVA: $F_{1,23}=3.14, \mathrm{p}=0.07$ ). The significant density effect reported in Table 1 highlighted that some brown and yellow colour morphs were observed at higher densities in bright and dark compartments, respectively, whereas both yellow or brown morphs were observed in bright and dark compartments at the lowest density (1 fish per compartment) (Fig. 1). The Habitat $\times$ Density interaction was also significant (Table 1), revealing a different magnitude in the factor habitat at each level of density. 
Table 1. Results of tests (2-way ANOVA and ANCOVA) for density and habitat effects on the percentage of brown colour morphs 5, 10 and $15 \mathrm{~d}$ post-settlement. The percentage of brown morphs (arcsine-square root transformed) was considered as an independent variable, with density and habitat as fixed factors. Covariates of the percentage of brown colour morphs at 5 and $10 \mathrm{~d}$ were used in the models for 10 and $15 \mathrm{~d}$, respectively. See 'Materials and methods' for the calculation of the percentage of brown morphs. Replicate samples sizes were 7 and 6 (corresponding to 46 and 108 individual fish) for low and high densities, respectively, in both dark and bright habitats. Bold values indicate significance at $\mathrm{p}<0.05$

\begin{tabular}{|c|c|c|c|c|c|c|c|c|c|}
\hline \multirow[t]{3}{*}{ Source } & & & & \multicolumn{3}{|c|}{$\%$ brown morphs } & \multirow[b]{3}{*}{$\mathrm{df}$} & \multirow{3}{*}{$\begin{array}{c}-15 \mathrm{~d} \\
F\end{array}$} & \multirow[b]{3}{*}{$\mathrm{p}$} \\
\hline & & $-5 \mathrm{~d}-$ & 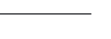 & & $-10 d$ & & & & \\
\hline & df & $F$ & $\mathrm{p}$ & df & $F$ & $\mathrm{p}$ & & & \\
\hline Intercept & 1 & 774.25 & $<0.001$ & 1 & 0.43 & 0.52 & 1 & 5.75 & 0.03 \\
\hline Habitat change & 1 & 15.68 & 0.001 & 1 & 0.27 & 0.61 & 1 & 20.47 & $<0.001$ \\
\hline Density & 1 & 363.22 & $<0.001$ & 1 & 0.31 & 0.58 & 1 & 0.01 & 0.95 \\
\hline Habitat $\times$ Density & 1 & 23.10 & $<0.001$ & 1 & 0.71 & 0.41 & 1 & 0.09 & 0.76 \\
\hline Covariate & & & & 1 & 0.13 & 0.72 & 1 & 0.08 & 0.78 \\
\hline Residual & 22 & & & 21 & & & 21 & & \\
\hline
\end{tabular}
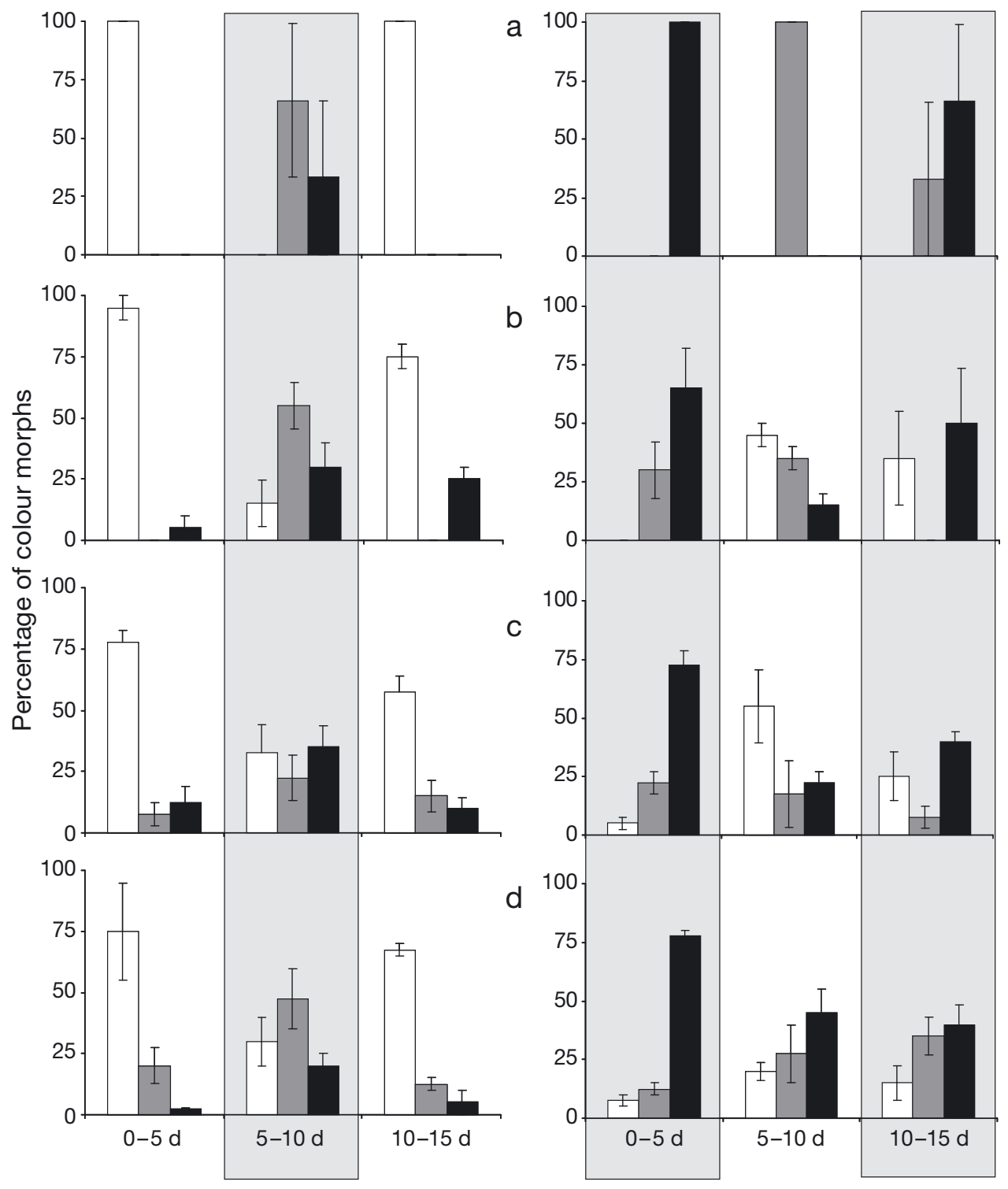

Days post-settlement

\section{$\square$ Yellow morph \\ $\square$ Intermediate morph \\ - Brown morph}

Fig. 1. Chrysiptera leucopoma. Environmental effects on colour polymorphism 0 to $15 \mathrm{~d}$ post-settlement over 3 experimental removal-transfer treatments. The percentage of individuals showing one of 3 colour morphs is shown in relation to habitat background (bright vs. dark [shaded area] background) and conspecific density. Density treatments varied as follows: (a) 1 individual per compartment $(\mathrm{n}=3)$, (b) 5 individuals per compartment ( $\mathrm{n}=4)$, (c) 10 individuals per compartment $(\mathrm{n}=4)$ and $(\mathrm{d})$ 20 individuals per compartment $(n=2)$. Error bars are $\pm \mathrm{SE}$ 


\section{Juvenile colour morph flexibility and environmental cues}

\author{
5 to $10 \mathrm{~d}$
}

There was no difference in the proportion of juvenile brown morphs between either habitat or density after the habitat of origin ( 0 to $5 \mathrm{~d}$ post-settlement) had been changed from either dark to bright or from bright to dark (Table 1). However, if we consider the difference in the proportion of colour morphs following a habitat change, a significant effect of habitat change was found (Table 2). Juveniles changed to the brown morph when moved from a bright to a dark habitat, and changed away from the brown morph (to the yellow morph) when moved from a dark to a bright habitat at both low and high densities (MANOVA, low density: $F_{1,23}=18.85, \mathrm{p}<0.001$; high density: $F_{1,23}=$ 9.13, $\mathrm{p}=$ 0.006; Fig. 1).

\section{0 to $15 \mathrm{~d}$}

A difference in the proportion of brown morphs was found between habitats after juveniles had been returned to their habitat of origin ( 0 to $5 \mathrm{~d}$ post-settlement; Table 1, Fig. 1). More brown morphs were found in dark habitats at both low and high densities (MANOVA, low density: $F_{1,23}=14.61, \mathrm{p}=0.001$; high density: $F_{1,23}=10.06, \mathrm{p}=0.004$; Fig. 1). A significant effect of habitat was also found on the difference in the proportion of morph colour following a habitat change from 10 to $15 \mathrm{~d}$ post-settlement (Table 2). High colour flexibility was seen in Chrysiptera leucopoma indi-

Table 2. Results of 2-way ANOVA for density and habitat effects on the change in percentage of brown colour morphs from 5 to $10 \mathrm{~d}$ and from 10 to $15 \mathrm{~d}$ post-settlement. The difference in the percentage of brown morphs (arcsine-square root transformed) was considered as an independent variable, with density and habitat change as fixed factors. Replicate samples sizes were 7 and 6 (corresponding to 46 and 108 individual fish) for low and high density, respectively, in both dark and bright habitats. Bold values indicate significance at $\mathrm{p}<0.05$

\begin{tabular}{|c|c|c|c|c|c|c|}
\hline \multirow[t]{3}{*}{ Source } & \multicolumn{6}{|c|}{ Difference in \% brown morphs } \\
\hline & & -5 to 1 & $0 \mathrm{~d}-$ & & 10 to & $15 \mathrm{~d}-$ \\
\hline & $\mathrm{df}$ & $F$ & $\mathrm{p}$ & $\mathrm{df}$ & $F$ & $\mathrm{p}$ \\
\hline Intercept & 1 & 1.84 & 0.19 & 1 & 1.31 & 0.27 \\
\hline Habitat change & 1 & 183.79 & $<0.001$ & 1 & 25.64 & $<0.001$ \\
\hline Density & 1 & 1.96 & 0.18 & 1 & 0.09 & 0.77 \\
\hline $\begin{array}{l}\text { Habitat change } \times \\
\text { Density }\end{array}$ & 1 & 3.19 & 0.09 & 1 & 0.51 & 0.48 \\
\hline Residual & 22 & & & 22 & & \\
\hline
\end{tabular}

viduals up to 15 post-settlement days of age, and fish changed body colour to yellow and brown in bright and dark habitat backgrounds, respectively, at both low and high densities (MANOVA, low density: $F_{1,23}=$ 122.39, $\mathrm{p}<0.001$; high density: $F_{1,23}=61.74, \mathrm{p}<0.001$; Fig. 1).

\section{Adult colour morph flexibility and environmental cues}

In the adult experiments, only 5 of the 136 yellow morphs changed to a brown colour after $5 \mathrm{~d}$ in the dark habitat background, and none of the adult brown morph changed to a yellow colour (i.e. no significant effect of either habitat or density on adult yellow morphs; Table 3, Fig. 2).

Table 3. Results of 2-way ANOVA for density and habitat effects on the percentage of adult yellow colour morphs. The percentage of yellow morphs (arcsine-square root transformed) was considered as an independent variable, with density and habitat change as fixed factors. Bold values indicate significance at $\mathrm{p}<0.05$

\begin{tabular}{|lccc|}
\hline \multirow{2}{*}{ Source } & \multicolumn{3}{c}{$\%$ yellow morphs- } \\
\cline { 2 - 4 } & df & $F$ & $\mathrm{p}$ \\
\hline Intercept & $\mathbf{1}$ & $\mathbf{3 8 0 . 2 2}$ & $<\mathbf{0 . 0 0 1}$ \\
Habitat change & 1 & 0.49 & 0.49 \\
Density & 1 & 0.96 & 0.34 \\
Habitat change $\times$ Density & 1 & 0.49 & 0.49 \\
Residual & 29 & & \\
\hline
\end{tabular}

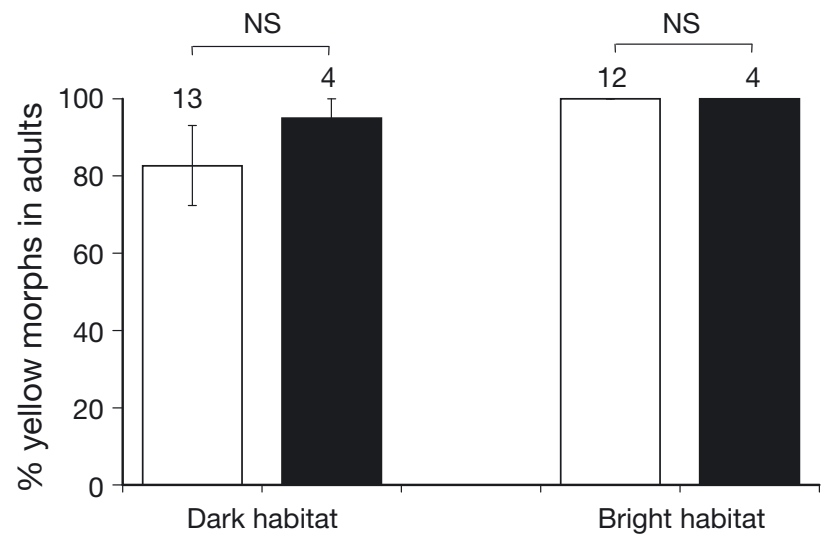

Fig. 2. Chrysiptera leucopoma. Environmental effects on colour polymorphism of adults. The percentage of adult yellow morphs is shown in relation to habitat background (bright vs. dark habitat) and conspecific density (black and white bars refer to high and low densities, respectively) in which they had been placed for $5 \mathrm{~d}$. Sample sizes are indicated above each bar. NS $=p>0.05$ from MANOVA simple-effects analyses. Error bars are $\pm \mathrm{SE}$ 


\section{DISCUSSION}

Chrysiptera leucopoma larvae at settlement in the present study adopted a body colouration in response to their habitat. Colour change was found to be plastic, at least for individuals up to 15 post-settlement days of age, despite the fact that our results could also partially appear as a residual effect of the original colour. Future experiments should be performed with varied time periods of treatments in order to precisely determine the extent of the flexibility period. The majority of individuals changed to yellow when the habitat became bright and to brown when the habitat became dark. Finally, almost no C. leucopoma adults changed their body colour. However, the few that did suggest that adults could be slower to change their colour body or that the habitat cues might have been less appropriate for adults.

Colour polymorphism may be linked to gender and maintained by sexual selection (Owens \& Hartley 1998). However, there are a variety of animals in which colour polymorphism is not linked to sexual function; therefore, other mechanisms must also be involved in the evolution and maintenance of colour variation. Different morphs may be maintained if there is a difference in the habitat in which each morph gains the greatest fitness (e.g. Forsman \& Appelqvist 1999, Gray \& McKinnon 2007). Our lab experiments highlighted that the colour dimorphism of Chrysiptera leucopoma was influenced predominantly by habitat background. All C. leucopoma larvae that colonized Rangiroa Lagoon were yellow in colour, and when they were assigned to a bright habitat background they maintained their yellow morph. However, when they were assigned to a dark habitat background, they changed to a brown morph. These laboratory results are consistent with field surveys. Some studies have shown that yellow C. leucopoma adults were usually found in bright habitats on live coral colonies and coral rubble, while brown adults usually lived cryptically in dark habitats hiding in places of coral slab and beach-rock (Lecchini 2003, Lecchini \& Galzin 2005). During the juvenile phase, the brown morphs seem to be highly cryptic because they are exceptionally encountered on the reef in comparison with yellow morphs (Lecchini \& Galzin 2005). Interestingly, this behaviour is relatively similar in aquaria, where brown juveniles remain mostly close to the bottom, whereas yellow morphs swim throughout the aquaria. The spatial distribution of $C$. leucopoma colour morphs between habitats could be explained by fitness differences in relation to habitat associations. Different rates of predation between habitats could underlie fitness differences among colour variants in many colour polymorphic species (for review, see Bond \& Kamil 2006).

However, conspecific density also played a role, albeit minor, in colour change. Colour change to brown was more frequent at high rather than at low densities in bright habitats during the first 5 post-settlement days. At the higher densities, we observed that juveniles were more aggressive defending some parts of the aquaria. This territorial behaviour could be linked to the induction of colour change. Density-dependent polyphenism is well known in insects such as the desert locust Schistocerca gregaria (Sword 1999) and the American grasshopper S. americana (Tanaka 2004). In $S$. gregaria, density-dependent change in colour represents a component of an aposematic strategy where high density level induces a change from cryptic to warning colouration (Sword 1999). In Chrysiptera leucopoma, the role of density-dependent colour change will have to be clarified by some additional experiments and the densities used in aquaria should be linked to the conspecific density in the wild.

Lastly, our results showed that colour flexibility of Chrysiptera leucopoma occurred mainly during the first 15 post-settlement days, but not during the adult stage (except for 5 individuals). Lecchini \& Galzin (2005) showed that some coral reef fish species explored different habitats during the first post-settlement days, before settling on one habitat. For these species, colour flexibility directly induced by an environmental cue (i.e. habitat) during the first post-settlement days could be advantageous for undertaking different ontogenetic shifts in habitat associations before their recruitment into the adult population. Thus the colour flexibility of C. leucopoma (yellow to brown morph and vice versa) during the first 15 post-settlement days would allow them to explore different live coral, coral rubble, beach-rock and coral slab habitats and to select one according to success in prey capture, predation pressure, food availability and the density of conspecifics already settled.

Overall, the present study is one of the first to explore the proximate causes of colour polymorphism at different life stages of a coral reef fish and to highlight colour morph flexibility according to habitat background (see also Booth 1990, Hoffman \& Blouin 2000, Messmer et al. 2005, Wilson et al. 2007, Detto et al. 2008). However, we found that some Chrysiptera leucopoma acquired a brown morph in a bright environment, whilst others kept their yellow morph in dark habitats. These results suggest that other determinants (e.g. food composition, food availability or temperature) may also induce the colour morph differentiation during the ontogeny of C. leucopoma.

Acknowledgements. This research was supported by grants from La Communauté Française de Belgique (Concours des bourses de voyage 2007), Agence nationale de la recherche (ANR-06-JCJC-0012-01), Ministère de l'Outer-Mer (MOM, 06 PF 15) and the Coral Reef Initiative in the South Pacific Program (C2A). 


\section{LITERATURE CITED}

Allen GR (1991) Damselfishes of the world. Mergus, Melle

Bond AB, Kamil AC (2006) Spatial heterogeneity, predator cognition, and the evolution of color polymorphism in virtual prey. Proc Natl Acad Sci USA 103:3214-3219

Booth CL (1990) Evolutionary significance of ontogenetic colour change in animals. Biol J Linn Soc 40:125-163

Detto T, Hemmi JM, Backwell PRY (2008) Colouration and colour changes of the fiddler crab, Uca capricornis: a descriptive study. PLoS ONE 3:e1629

Field A (2005) Discovering statistics using SPSS. The Alden Press, Oxford

> Forsman A, Appelqvist S (1999) Experimental manipulation reveals differential effects of colour pattern on survival in male and female pygmy grasshoppers. J Evol Biol 12:391-401

Gray SM, McKinnon JS (2007) Linking color polymorphism maintenance and speciation. Trends Ecol Evol 22:71-79

Hoffman EA, Blouin MS (2000) A review of colour and pattern polymorphisms in anurans. Biol J Linn Soc 70:633-665

Lecchini D (2003) Identification of habitat use strategies between the colonisation and recruitment stages of coral reef fish in the lagoon of Moorea (French Polynesia): approach by behavioural ecology. PhD thesis, University of Paris VI

Lecchini D, Galzin R (2005) Spatial repartition and ontogenetic shifts in habitat use by coral reef fishes (Moorea, French Polynesia). Mar Biol 147:47-58

Lecchini D, Dufour V, Carleton J, Strand S, Galzin R (2004) Study of the fish larval flux at Moorea Island: is the spatial scale significant? J Fish Biol 65:1142-1146

Editorial responsibility: Hans Heinrich Janssen, Oldendorf/Luhe, Germany
Leimar O (2007) Environmental and genetic cues in the evolution of phenotypic polymorphism. Evol Ecol 42:21-32

Lo-Yat A (2002) Variabilité temporelle de la colonisation par les larves de poissons de l'atoll de Rangiroa (Tuamotu, Polynésie Française) et utilisation de l'outil « otolithe » de ces larves. PhD thesis, Université de la Polynésie Française, Tahiti

- Messmer V, Jones GP, van Herwerden L, Munday PL (2005) Genetic and ecological characterisation of colour dimorphism in a coral reef fish. Environ Biol Fishes 74:175-183

> Munday PL, Eyre PJ, Jones GP (2003) Ecological mechanisms for coexistence of colour polymorphism in a coral reef fish: an experimental evaluation. Oecologia 137:519-526

Nijhout HF (2003) Development and evolution of adaptive polyphenisms. Evol Dev 5:9-18

Noor MAF, Parnell RS, Grant BS (2008) A reversible color polyphenism in American peppered moth (Biston betularia cognataria) caterpillars. PLoS ONE 3:31-42

Owens IPF, Hartley IR (1998) Sexual dimorphism in birds: Why are there so many different forms of dimorphism? Proc R Soc Lond B 265:397-407

Sword GA (1999) Density-dependent warning coloration. Nature 397:217

Tanaka S (2004) Environmental control of body-color polyphenism in the American grasshopper, Schistocerca americana. Ann Entomol Soc Am 97:293-301

> Wilson D, Heinsohn R, Legge S (2006) Age- and sex-related differences in the spatial ecology of a dichromatic tropical python (Morelia viridis). Austral Ecol 31:577-587

Wilson D, Heinsohn R, Endler JA (2007) The adaptive significance of ontogenetic colour change in a tropical python. Biol Lett 3:40-43

Submitted: January 11, 2010; Accepted: May 3, 2010

Proofs received from author(s): May 31, 2010 